\title{
Pathogenicity of fungi associated with the leaf spot disease of Eggplant (Solanum aethiopicum L.) in a derived savannah zone
}

\author{
Mbadianya, J.I ${ }^{1}$, Echezona, B.C. ${ }^{2}$, Ugwuoke K.I ${ }^{3}$, Wokocha, R.C. ${ }^{4}$ \\ ${ }^{1}$ Department of Crop Science, University of Nigeria, Nsukka, Nigeria \\ ${ }^{2}$ Department of Crop Science, University of Nigeria, Nsukka, Nigeria \\ ${ }^{3}$ Department of Crop Science, University of Nigeria, Nsukka, Nigeria \\ ${ }^{4}$ Michael Okpara University of Agriculture, Umudike, Nigeria
}

\begin{abstract}
A study was carried out on the leaf spot disease of eggplant (Solanum aethiopicum L.) in Nsukka derived savannah zone. Helminthosporium infestans Butler and Jones, Cladophialophora carrionii Trejos, Aspergillus niger Them and Rapet, Rhizopus nigricans Ehhrenb and Neurospora africana Shear and Dodge were isolated from the diseased plants. Helminthsporium.infestans was the most frequently isolated organism from the infected leaves (61.11\%) being glaringly higher in frequency of occurrence than A. niger (5.56\%), C. carrionii (11.11\%), R. nigricans (5.56\%) and N. africana (16.67\%). The pathogenicity tests on susceptible eggplant variety Solanum aethiopicum $L$. using all fungal isolated, showed that only $H$. infestans was pathogenic on the test crop. It produces the characteristic symptom of dark brown spots with concentric rings on the leaves, which gave target board effect on 28 days after inoculation. H. infestans was re-isolated from the infected leaves of the Eggplant. The observation of the characteristic symptom of dark yellow-brown spots with concentric rings on the leaves and re-isolation of the pathogen from infected leaves confirmed that $H$. infestans incited the leaf spot disease on the leaves. The other fungi also isolated may have played a synergistic role in the disease development.
\end{abstract}

Keywords: Eggplant (Solanum aethiopicum L), Inoculation, Isolation, Leaf spot disease of eggplant, Pathogenicity test.

\section{Introduction}

The African eggplant (Solanum aethiopicum L.), known as garden egg, añara, etc. is one of the important vegetable crops grown almost worldwide. It is essentially a warm weather crop which extensively grows in Eastern and Southern Asia, including India, USA, Bangladesh, Pakistan, China, Japan, and the Philippines. It is also popular in Egypt, France, Italy (Tindall, 1983). According to FAO 1994 Production Year Book, the world eggplant production land area was 556,000 ha, and the total production was 8, 979,000 metric tons. Gill and Tomar (1991) reported 299,770 ha of eggplant production area in India, and 29,150 ha in Bangladesh in 1992-93. Eggplant can be grown in all parts of Nigeria all the year round.

Plant is a perennial or annual deciduous shrub with or without prickles, up to $2 \mathrm{~m}$ tall; stems much-branched; roots extending both vertically and laterally; leaves alternate, simple, petiole up to $11 \mathrm{~cm}$ long, ovate-elliptic with an acute apex, $12-30 \times 4-21 \mathrm{~cm}$, entire or lobate-dentate, pinnately veined; inflorescences lateral racemose cymes, up to 12 flowers; flowers bisexual, regular, 4-10-merous; pedicel 2-15 mm long, yellow; fruit (berries) globular to depressed globular, elliptic in outline, egg-shaped or spindle-shaped, 1-6 cm long, smooth to grooved, red or orange, many-seeded; seeds lense-shaped to kidney-shaped, flattened, 2-5 $\mathrm{mm}$ across, pale brown or yellow; epigeal germination.

The fruit can be eaten in various forms without the need for an elaborate preparation. It can be eaten raw or cooked (Organ, 1960; Huxley, 1992). It can be baked, stewed or added to soups, curries, etc. (Facciola, 1990). The eggplant is used mainly as a crop, but it does have various medical uses that make it a valuable addition to the diet. In particular, the fruit helps to lower blood cholesterol levels and is suitable as part of a diet to help regulate high blood pressure (Chiej, 1984; Chevalier, 1996). The fruit is anti-haemorrhoidal and hypotensive (Chiej, 1984). It is also used as an antidote to poisonous mushrooms. It is bruised with vinegar and used as a poultice for cracked nipple, abscesses and haemorrhoids (Duke and Ayensu, 1985). The leaves are toxic and should only be used externally (Chevalier, 1996). The African eggplant (Solanum aethiopicum L.) is affected by several fungal diseases which inflict heavy losses in its production. One of such fungal disease is the Leaf spot disease. Lower leaves are attacked first and then the disease progresses upwards. Dark brown spots with concentric rings develop on the leaves, which give target board effect, the most characteristic symptom of the disease. In severe attacks, affected leaves shrivel and fall down prematurely resulting in early defoliation. On the leaves, the spots appear as small angular scattered, light brown in colour, progressing between veins towards the leaflet margin. The severely infected leaflets curl and dry out prematurely. Subsequently, the pathogen invades the adjoining healthy leaflets and gradually progresses on the foliage upwards from the most infected 
leaves. Elongated dark brown lesion also appears on the stem and branches. This research work is to study the leaf spot diseases of African eggplant with the following objectives:

1. To isolate and identify organism(s) responsible for leaf spot disease of eggplants

2. To determine the pathogenicity of these organisms

\section{Materials and Method}

Two experiments; one laboratory and one greenhouse were carried out at the Department of Crop Science, University of Nigeria, Nsukka. Nsukka is located in the derived Savannah Zone $\left(06^{\circ} 52^{\prime} \mathrm{N}, 07^{\circ} 24^{`} \mathrm{E}\right.$ and altitude of 447.26 meters above sea level).

\subsection{Experiment}

2.1. Determination of the pathogenicity of fungi isolates on African eggplants in green house The procedures adopted were;

\subsection{1. (i) Disease survey for the incidence and severity of leaf spot diseases of African eggplant}

Disease survey was conducted on Solanum aethiopicum farm in order to assess the level of leaf spot disease infection. The farm was the 4th year students' practical eggplant farm located at the Department of Crop Science Research Farm, University of Nigeria, Nsukka. The size of the farm was $150 \mathrm{~m}$ x $200 \mathrm{~m}$ with a plant population of 4500 . The field was transplanted on $17^{\text {th }}$ April, 2012 and the sampling started from the one week after transplanting. Out of the existing field, data were taken from the plot size of $50 \mathrm{~m} \mathrm{x} 90 \mathrm{~m}$. The soil type is tropical ultisol with $\mathrm{pH}$ of 5.0-6.5. In the farm, two diagonal transects were taken across and Solanum plants on every $1 \mathrm{~m}$ distance along transect were sampled for disease occurrence. Therefore, 50 plants were sampled in each transect making a total of 100 samples for the two transects. The plant spacing was $1 \mathrm{~m} \mathrm{x} 1 \mathrm{~m}$ on the two sides of the bed. The disease incidence was estimated by counting the number of plants infected within the sampled area of the field and expressing this figure as a percentage of the total number of plants sampled. The disease incidence and severity were collected for 30days.

Disease incidence and severity were assessed based on Wokocha (1990)

Disease incidence $(\mathrm{I})=\quad$ Number of plant units affected $\mathrm{x} 100$

$$
\text { Total number (healthy and infected of units assessed) }
$$

Disease severity was recorded on the following scale:

$0=$ No visible disease symptom

$1=$ less than $15 \%$ of leaves infected

$2=15 \%-35 \%$ of leaves infected

$3=36 \%-49 \%$ of leaves infected

$4=50 \%-74 \%$ of leaves infected

$5=$ more than $75 \%$ of leaves infected

Numerical rating similar to these have used by Wokocha (1990) to assess Soybean plants by Macrophomina phaseolina.

\subsection{Isolation and identification of the pathogens associated with diseased eggplants \\ 2.2.1.Procedures for isolation of the pathogen}

Agar plate method was adopted where the diseased leaves were cut into $5 \mathrm{~mm}$ pieces, thoroughly washed under running tap water, surfaced sterilised in $0.1 \%$ mercuric chloride and rinse three times in distilled water. The pieces were then plated ( 3 pieces per plate) on water Agar and incubated for three day before transferring the colony growth observed to fresh Potato Dextrose Agar (PDA) medium impregnated with streptomycin and incubated for 7 days at $28^{0} \mathrm{C}$. Two drops of streptopenicillin taken from $125 \mathrm{mg}^{-1}$ of streptopenicillin solution, (a mixture of streptomycin $62.5 \mathrm{mg}^{-1}$ and penicillin $62.5 \mathrm{mg}^{-1}$ (Gupta and Barnerjee, 1970; Wokocha and Okereke, 2005). The antibiotic was added to each plate to inhibit bacteria growth. Pure cultures were obtained by sub-culturing three times in PDA. Pure cultures of the final isolates were maintained on PDA slants in test tubes in the refrigerator until required.

\subsubsection{Identification of Pathogens}

Wet mounts of pure cultures were observed under binocular microscope at X40 magnification for fungal growth while the identification of the isolated fungi were carried out based on their cultural characteristics and with the help of identification scheme (Barnett and Hunter, 1972).

The name of each fungus and dates of inoculation were labeled on the plates. They were incubated at 
room temperature $\left(23 \pm 2^{\circ} \mathrm{C}\right)$ in a laminar flow for seven (7) days and their growth observed. The frequencies of occurrence of the different types of fungi associated with eggplant diseases were determined. The number of times each fungus was encountered was recorded.

The percentage frequency of occurrence was calculated with the formula (Ebele, 2011).

Number of times a fungus was encountered X 100

Total fungal isolations

\subsubsection{Composition and Preparation of different types of Culture Media}

The media used were Potato Dextrose Agar and Water Agar.

\section{Composition of PDA and Water agar}

\begin{tabular}{|c|c|c|}
\hline \multicolumn{2}{|l|}{ Composition } & Grams/ Litre \\
\hline Potatoes Infusion form & 2 & 200.00 \\
\hline Dextrose & 2 & 20.00 \\
\hline Agar & 1 & 15.00 \\
\hline B Bacto agar & 1 & 15 \\
\hline Distilled water & 11 & 1 \\
\hline $\mathrm{Fi} \quad$ Final $\mathrm{pH}\left(\right.$ at $\left.25^{\circ} \mathrm{C}\right)$ & & $5.6 \pm 0.2$ \\
\hline
\end{tabular}

\subsubsection{Preparation of PDA}

Thirty nine grams of PDA was suspended in $1000 \mathrm{ml}$ of cold distilled water in a conical flask. The conical flask was closed with a tight cotton plug and heated to boiling to dissolve the medium completely. It was then sterilized by autoclaving at $15 \mathrm{lbs}$ pressure at $121^{\circ} \mathrm{C}$ for 15 minutes and allowed to cool to $45^{\circ} \mathrm{C}$ before being dispensed in sterilized petri plates. The media was finally allowed to solidify before use.

Readymade PDA sourced from Joechem laboratories Ltd Nsukka was used for the study.

\subsubsection{Preparation of water agar}

Fifteen grams of Bacto Agar was suspended in $1000 \mathrm{ml}$ of cold distilled water in a conical flask and heated to boiling to dissolve the medium completely and the flask was then closed with a tight cotton plug. It was then sterilized by autoclaving at $15 \mathrm{lbs}$ pressure at $121^{\circ} \mathrm{C}$ for 15 minutes. After sterilization, it was cooled to $45^{\circ} \mathrm{C}$ and distributed in sterile petri plates and allowed to solidify before use.

Materials used were Potato Dextrose agar (PDA), diseased plants, sterilized petri dishes, distilled water, Bacto-agar, cotton wool, streptomycin, syringes, test tubes, Autoclave, Electric balance, air Hot oven, Incubator, Microscopes, Refrigerator, Dimethyl Sulfoxide, Beakers, Microscopic slides, Cork borer, Inoculating loop and $\mathrm{pH}$ meter.

\subsection{Preparation of the inoculums suspension}

The isolates obtained were grown on potato dextrose broth for 5 days. Hyphal mat from 5 day old Potato broth cultures of the Pathogens were scraped asceptically onto a fine cheese cloth, filtered and washed in several changes of sterile distilled water to remove traces of stalling materials. The mat were then transferred asceptically into $200 \mathrm{ml}$ of distilled water containing $5 \mathrm{ml}$ glucose solution in waring blender and homogenized for one minute at low speed in order to get the inocula ready for pathogenicity test on eggplant (Wokocha et al., 1986).

\section{4 . Soil sterilization}

This was conducted in the Department of Crop Science greenhouse, University of Nigeria Nsukka under the mean temperature of $28^{\circ} \mathrm{C}$.

The top soil collected at $0-30 \mathrm{~cm}$ depth, manure and river sand mixed at the ratio of 3:2:1 were heat-sterilized in a cut covered metal drum using firewood at $100^{\circ} \mathrm{C}$ for 15 minutes and allowed to cool. The sterilized soil was dispensed into Black polythene bags of $30 \mathrm{~cm}$ x $29 \mathrm{~cm}$ and used to raise the eggplant seedlings in the nursery.

The seedlings were transplanted after five weeks old on Black polythene bags filled with $400 \mathrm{~g}$ sterilized soil at the rate of two seedlings per bag. The inoculation was by foliar spray. Eggplant seedlings (7 weeks old) were inoculated. The five pathogens isolated were inoculated separately on the seedlings and replicated 5 times. Non inoculated control seedlings were similarly treated with distilled water. All the seedlings were placed on benches in the green house in a Completely Randomized Design (CRD) at mean temperature of 
$25^{0}-28^{0} \mathrm{C}$

\subsection{Study on the leaf spot disease organism (Helminthosporium infestans).}

After establishing the causal organism, the green house pathogenicity test was repeated with Helminthosporium infestans. Disease incidence and severity were determined in up to 100 plants. Data collection was made over a period of 30 days after inoculation.

\section{Results}

The Mean Disease incidence and severity of the leaf spot diseases of eggplant taken for period of 30 days.

The result of the disease survey on the eggplant farm taken for period of 30 days (Table 1) showed that the rate of infection of the pathogen increased remarkably as the sampling days increased. For every 100 plant sampled, 18 plants were infected at as $3^{\text {rd }}$ day of sampling while $90 \%$ of the plants were affected at the $30^{\text {th }}$ day of sampling. The degree of damage (severity) also increased progressively in the same manner with the incidence. From, $12^{\text {th }}$ day to $30^{\text {th }}$ day, the severity is above $75 \%$ of the infection. The presence of the leaf spot on eggplant is a confirmation that eggplant is vulnerable to fungi attack.

Table1: the Mean Disease incidence and severity of the leaf spot diseases of Eggplant farm taken for period of 30 days.

\begin{tabular}{llccl}
\hline Days & Sampled plants & Infected plants & Disease incidence & $\begin{array}{l}\text { Disease } \\
\text { severity }\end{array}$ \\
\hline 3 & & & 18 & 1 \\
6 & 100 & 18 & 36 & 1 \\
9 & 100 & 36 & 46 & 4 \\
12 & 100 & 46 & 69 & 4 \\
15 & 100 & 69 & 70 & 5 \\
18 & 100 & 70 & 74 & 5 \\
21 & 100 & 74 & 79 & 5 \\
24 & 100 & 79 & 80 & 5 \\
27 & 100 & 80 & 82 & 5 \\
30 & 100 & 82 & 90 & 5 \\
\hline
\end{tabular}

Disease incidence (\%)

\section{Fungi associated with the Eggplant Leaf spot disease and their percentage frequencies of} occurrence.

A total of five different fungi were isolated from the infected Eggplant leaves (table 2). They were Helminthosporium infestans Butler and Jones, Cladophialophora carrionii Trejos, Aspergillus niger Thom and Raper, Rhizopus nigricans Ehhrenb and Neurospora Africana Shear and Dodge.

Aspergillus niger on the PDA plates was black when observed with ordinary eyes, under the microscope, Aspergillus niger had profused branched septate, hyaline and well developed hypae with an abundance of conidiophores (Plate1). The conidiophores were long and erect each terminating in a bulbous head called vesicle. The conidia were born in chains. Combining these microscope and macroscopic features, the organism was confirmed as Aspergillus niger. In Helminthosporium infestans, conidiophores are determinate, ceasing growth with production of apical conidia, relatively short and simple or sparingly branched. (Barnett and Hunter, 1972). In Rhizopus, the sporangia are supported by a large apophysate columella, and the sporangiophores arise among distinctive rhizoids. Singh, (1998). Neurospora species are molds with broadly spreading colonies, with abundant production of ascomata. Ascomata are superficial or immersed, perithecial and ostiolate or cleistothecial and non-ostiolate, hairy or glabrous, dark coloured. Peridium membranaceous, asci cylindrical, clavate or subspherical, with a persistent or evanescent wall, usually with a thickened and non-amyloid annular structure at the apex, usually 8-spored. Ascospores broadly fusiform, ellipsoidal, or nearly spherical, unicellular, hyaline to yellowish brown or olive-brown, becoming dark and opaque at maturity, (Ho, 1986).

Cladophialophora carrionii (Trejos): the conidia are smaller and comprise heavily branched systems which fall apart much more easily than in the other Cladophialophora species, McGinnis (1980), Rippon (1988), de Hoog et al. (1995) and de Hoog et al. (2000).

Helminthosporium infestans has the highest percentage of occurrence (61.11\%) while Aspergillus niger and Rhizopus nigricans had the lowest percentage frequencies of occurrence (5.56\%). 
Table 2: Fungi associated with the Eggplant Leaf spot disease and their percentage frequencies of occurrence.

\begin{tabular}{lcc}
\hline Fungi & Number of pathogens & Percentage frequencies of occurrence (\%) \\
\hline H. infestans & 11 & 61.11 \\
C. carrionii & 2 & 11.11 \\
A. niger & 1 & 5.56 \\
R. nigricans & 2 & 5.56 \\
N. Africana & 3 & 16.67 \\
\hline
\end{tabular}

\section{Pathogenicity test}

The result of the pathogenicity test of all the five fungal isolates (Table 3) show that only Helminthosporium infestans was pathogenic on eggplant seedlings. It produces the characteristic symptom of dark brown spots with concentric rings development on the leaves, which gave target board effect 28 days after inoculation. Helminthosporium infestans was re-isolated from the infected leaves of the eggplant. The observation of the characteristic dark yellow-brown spots symptom with concentric rings on the leaves and the re-isolation of the pathogen from infected eggplant seedlings showed that Helminthosporium infestans incited the leaf spot disease of eggplant in this study. The other four fungi also isolated may have played a synergistic role in the development of the disease. Table 4 showed that the highest disease incidence (86\%) and severity (5) were recorded at 28 days after inoculation.

Table 3: Pathogenicity test

\begin{tabular}{llcc}
\hline Fungi & Pathogenicity & Disease incidence (\%) & $\begin{array}{c}\text { Disease } \\
\text { severity }\end{array}$ \\
\hline H. infestans & pathogenic & 86 & 5 \\
C. carrionii & Non pathogenic & 0 & 0 \\
A. niger & Non pathogenic & 0 & 0 \\
R. nigricans & Non pathogenic & 0 & 0 \\
$N$. Africana & Non pathogenic & 0 & 0 \\
\hline
\end{tabular}

Table 4: The Disease incidence and severity of the leaf spot diseases of Eggplant incited by Helminthosporium infestans taken for $\mathbf{2 8}$ days after inoculation.

\begin{tabular}{lcc}
\hline Days & Disease Incidence $(\%)$ & Disease Severity \\
\hline 7 & 4 & 1 \\
14 & 15 & 1 \\
21 & 52 & 4 \\
28 & 86 & 5 \\
\hline
\end{tabular}

\section{Discussion}

The result of the disease survey on the eggplant farm taken for 30 days between April to May, 2012 showed that the rate of infection of the pathogen increased remarkably as the sampling days increased. The degree of damage (severity) also increased progressively in the same manner; this could be attributed to the low relative humidity, low rainfall and high temperature encountered at that period. The presence of leaf spot on eggplant confirmed the previous report of Adarsh (2010) that spots were found on eggplant leaves from March to August and its frequency was high in April and May. Five different fungi were isolated from the infected eggplant leaves. They were Helminthosporium infestans Butler and Jones, Cladophalophora carrionii Trejos, Aspergillus niger Thom and Raperr, Rhizopus nigricans thhrenb and Neurospora africana Shear and Dodge. Adarsh (2010) also isolated Helminthosporium infestans on the leaves of eggplant. Helminthosporium infestans had the highest percentage frequency of occurrence (61.11\%) while Aspergillus niger and Rhizopus nigricans had the lowest frequency of occurrence $(5.56 \%)$. Helminthosporium infestans may be the primary inoculum causing primary infection. The result of the pathogenicity test of all the fungal isolates showed that only Helminthosporium infestans was pathogenic on eggplant seedlings. It produced the characteristics symptom of dark brown spots with concentric ring on the leaves which gave the most severe effects 28 days after inoculation. This was similar to the characteristic symptoms of $H$. infestans described by (Gupta and Barnerjee, 1970). Helminthosporium infestans was re-isolated from the infected leaves of the eggplant. The observation of characteristic symptom of dark brown spots with concentric rings on the leaves and the re-isolation of the pathogen from the infected leaves showed that Helminthosporium infestans incited the spots found on the leaves of eggplant in the study. Other fungi isolated may be secondary invaders on the lesions caused by primary 
infection and hence could not incite spots on the leaves. This observation agreed with the reports of Flentje (1965) and Wilhelm (1967) showing that such organisms, when tested against the host in the absence of the primary pathogen would have no effect, also Colyer (1988) reported only mild virulence and considered the fungus to be a secondary invader.

\section{References}

[1]. Adarsh, Pandey (2010). Studies on fungal diseases of eggplant in relation to statistical analysis and making of a disease calendar. Recent research in Science and Technology, 2 (9): 01-03.ISSN:2076-5061. www.recent science.com

[2]. Barnett, H.L, and B.B. Hunter (1972). Illustrated General of Imperfect fungi, t3rd edition. Burgess Publishing Co. Minnesota. 241 Pp.

[3]. Butler, E. J. (1918). Fungi and Diseases in plants. Thacher Spink and Co. Calcutta, India. 300 Pp.Chadha, M. L.(1993).Improvement of b ' 'sd advances in horticulture (Eds.: Chadha,K. L. and Kalloo, G.) vol. 5 - vegetable crops.105-135.

[4]. Chevalier, A. (1996): The Encyclopaedia of Medicinal Plants. Dorling Kinderskey. London.

[5]. Chiej, R. (1984): Encyclopedia of Medicinal Plants. MacDonald.

[6]. Colyer, P. D. (1988). Frequency and pathogenecity of Fusarium spp. associated with seedling disease of cotton in Louisiana. Plant Disease 72: 400- 402

[7]. de Hoog, G.S., Gueho, E., Masclaux , F. (1995). Nutritional physiology and taxonomy of human-pathogenic Cladosporium-Xylohypha species. J. Med. Vet.Mycol. 33:339-347

[8]. de Hoog, G.S., Guarro, J., Gene, J. and Figueras, M.J. (2000). Atlas of Clinical Fungi (second edition). Centraalbureau voor Schimmelcultures, Utrecht, Netherlands.

[9]. Duke, J. A., and Ayensu, E.S (1985): Medicinal plants of China Reference Publications, Inc.

[10]. Ebele, M.I. (2011). Evaluation of aqueous plant extracts to control rot fungi in paw paw. Journal of Applied Biosciences 37:2419-2424.

[11]. Facciola, S. Cornupia (1990): A Source Book of Edible plants. Kampong publications.

[12]. FAO. (1995). Production Yearbook, 1994.

[13]. Flentje, N.T. (1965). Pathogenesis by soil fungi, pp. 255-268. In: Ecology of soil-borne plant pathogens (K.F. Baker and W.C. Snyder eds). Univ. of California Press, Berkeley, USA

[14]. Gill, H. and Tomar, B.( 1991). Vegetable Statistics at Glance Indian Agricultural Research Institute, New Delhi, India. Tech. Bull. No. 4.

[15]. Gupta, S and Barnerjee, A.B.(1970). Rapid method of screening antifungal antibiotic producing agents. Indianof Experimental Biology, 18:148-149.

[16]. Ho C.C. (1986). Identity and characteristics of Neurospora intermedia responsible for oncom fermentation in Indonesia. Food Microbiology 3(2):115-132.

[17]. Huxley, A. (1992): The new RHs Dictionary of gardening. Macmillan Press ISBN 0-333-47494-5.

[18]. McGinnis, M.R. (1980). Laboratory handbook of medical mycology. Academic Press

[19]. Organ, J. (1960): Rare Vegetables for Garden and Table. Faber

[20]. Singh, R.S. (1998). Diseases of vegetable crops. Oxford \& IBH Publishing Co. Pvt. Ltd., New Delhi. 363pp.

[21]. Tindall, H.D. (1983): Vegetables in the Tropics. Macmillan press. Ltd. London.

[22]. Wilhem, S. (1967). Parasitism and Pathogenesis of root disease fungi pp 356-366. In: Plant pathology, problems and progress 1908-1958. (C.S. Holton et al., eds) Central Book Depot, Allahabad.

[23]. Wokocha, R.C., Ebenebe, A. C and Erinle, I. D. (1986). Biological control of the basal stem rot disease of tomato caused by Corticium rolfsii (Sacc). Curzi in Nortern Nigeria. Tropical Pest Management 32(1): 35-39.

[24]. Wokocha, R.C, (1990). Integrated control of Sclerotium rolfsii infection of tomato in the Nigeria savanna: effect of Trichoderma viride and some fungicides. Crop protection 9:231-234.

[25]. Wokocha, R.C. and Okereke, V.C. (2005). Fungicidal activity of extracts of some medicinal plants on Sclerotium rolfsii, causal organism of the basal stem rot disease of tomato. Nigerian Journal of plant Protection, 22:106-111.

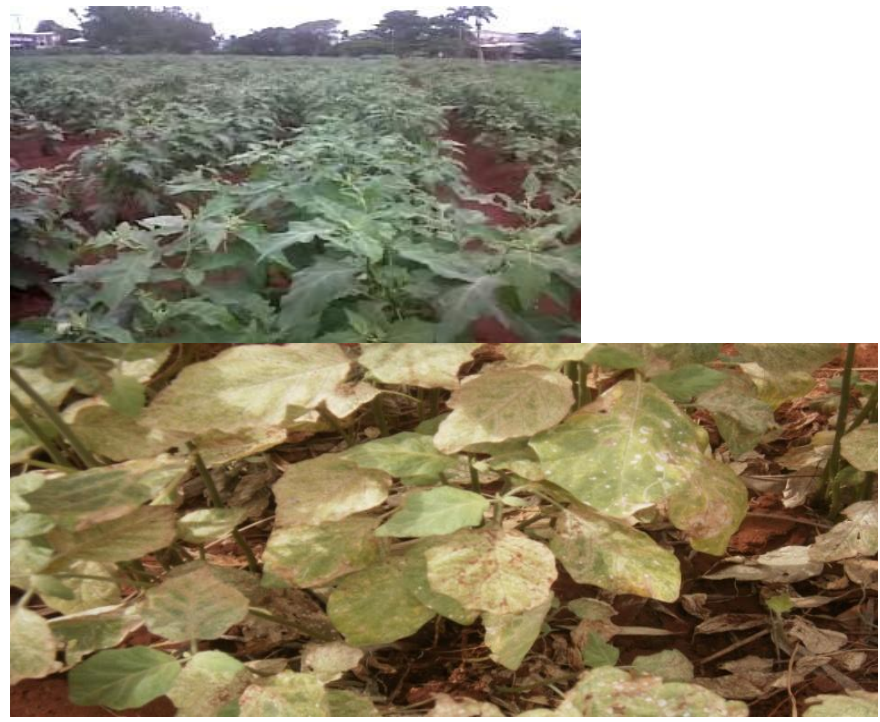

Solanum aethiopicum field Infested with leaf spot disease 


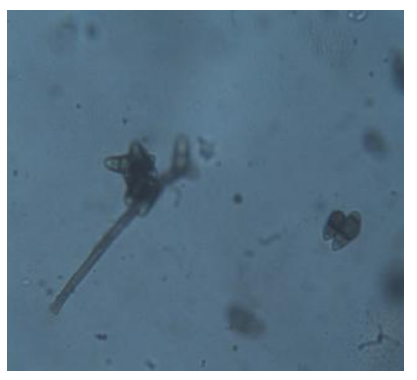

Helminthosporium infestans

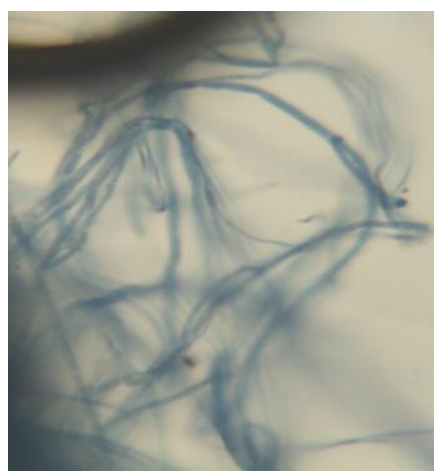

Neurospora spp

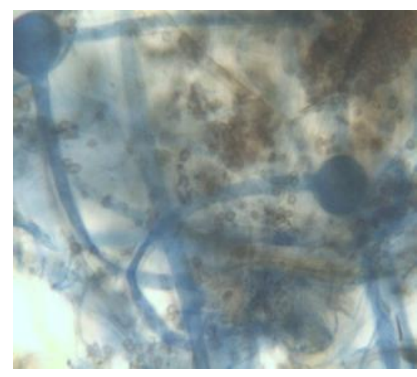

Rhizopus nigricans

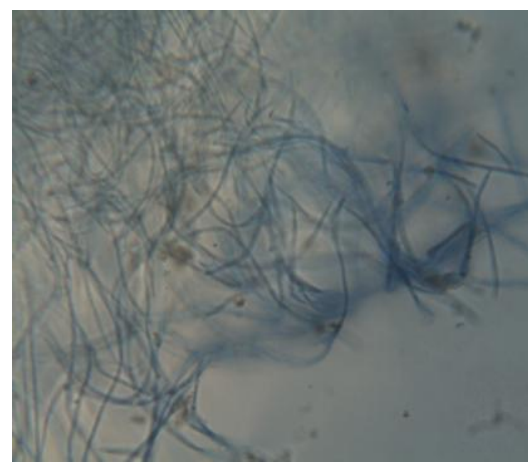

Cladophialophora carrionii Trejos

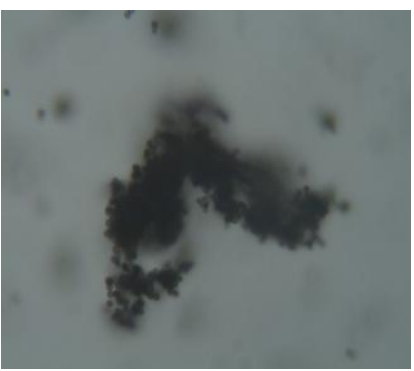

Aspergillus niger 